\title{
Solid waste management practice in Karachi through GIS techniques
}

\author{
Ambreen Afzal $^{1 *}$, Sheeba Afsar ${ }^{1}$ and Altaf Hussain Lahori ${ }^{2}$ \\ 1. Department of Geography, University of Karachi-Pakistan \\ 2. Department of Environmental Sciences, Sindh Madressatul Islam University, Karachi, 74000-Pakistan \\ *Corresponding author's email: ambreen.afzal@yahoo.com \\ Citation \\ AmbreenAfzal, Sheeba Afsar and Altaf Hussain Lahori. Solid waste management practice in Karachi through GIS \\ techniques. Pure and Applied Biology. Vol. 10, Issue 4, pp pp1258-1278. \\ http://dx.doi.org/10.19045/bspab.2021.100132 \\ Received: 22/01/2021 Revised: 23/02/2021 \\ Accepted: 24/02/2021 \\ Online First: 26/02/2021
}

\section{Abstract}

The extreme development of cities and subsequent enlarge in an urban population in recent years has led to a considerable enhance in consumptions and generations of solid waste material in the developing countries. The gradually rising population has led to several solid and hazardous waste issues in the megacity Karachi, due to unsatisfactory policies, laws, political instability, and poor municipal administration. The main purpose of this research work was to assess the issue of population density, waste generation, collection, transportation, and management of municipal solid waste through GIS techniques. The obtained results revealed that rising population density and improper collection of municipal solid waste from collections points had a negative impact on the total volume of waste generation. The open burning and disposal methods were very common to treat the municipal solid waste agenda. The collection of MSW from bins and transportation to a landfill site by vehicles was not accordingly in the city. No transfer station was buildup for the temporary deposition of MSW for further processing for recycling purpose. The private sector was involved in the recycling of MSW on a small scale and paying to afghan waste pickers to collect waste from located bins to dumping site. The workers were proliferating the waste around the bins and on the roads, due to lack of proper training. Overall, the present study indicated that the new advanced eco-friendly technologies viz., modified-composting, smart biochar, plastic tile, plastic roads, energy recovery etc., are urgent needed to manage MSW problems and minimize health issues and environmental degradation.

Keywords: Collection; GIS techniques; Municipal; Population density; Solid waste;

Transportation; Waste generation

\section{Introduction}

The multicultural megacity Karachi has been considered $2^{\text {nd }}$ largest Muslim city around the globe and facing various environmental issues including municipal solid waste management is an important issue, due to an increase in population density [1, 2]. According to statistical data revealed that the total population of Karachi city has reached about 14,910,352 during 2017. The population has been rapidly increasing day by day and possessing several solid and hazardous waste issues in the megacity, due to lack of awareness, training, budget, corruption, and poor municipal administration $[3,4]$. It is the largest big city of Pakistan with $10 \%$ of the total residents of a country and producing over 10,000 tons of 
MSW per day [5]. Furthermore, it has been observed in towns of Karachi which is also responsible for the increase of municipal waste (MSW) generation, while on the other active system of management [6]. MSW is a residential and commercial waste formed in public or notified sites, as well as treated biomedical wastes, however without industrial hazardous waste material [7]. The quantity of MSW generated in any given community is straight associated with in habitant growth, urbanization, industry, financial activities, and family unit consumption levels [8].

The modes of disposal of these wastes depend on the cultural practices of the people who live within the society, due to the ecological and human health issues collection, processing, transportation, recycling, and disposal of MSW are very important to waste management [9]. The quantity of MSW within the livelihood surroundings exerts pessimistic impacts on living beings. Also, concerning well-being, indiscriminate discarding of MSW enhances the risk of the spread of an extensive range of infectious disease [1]. Different strategies have been proposed for reducing, reusing, recycling, recovering energy, and disposing of solid waste Guerrero et al. [10], but these strategies are controversial according to the environmental impacts [11-13]. Furthermore, MSW is a universal issue and a big challenge for healthy life and sustainable environment [14]. It is a big challenge for the living-beings of the entire globe. Impact assessment is a precautionary and safety tool for the environment, which makes it probable to fulfill with ecological effective policies, and even incorporate early such policies into the expansion and decision-making processes [15].

In the former study, Yesilnacar and Cetin [16] conducted research work on the location of suitable sites for the discarding of toxic waste using geological, topography, and land-use system. Furthermore, Chang et al.
[17] assessed a multi-criteria decisionmaking technique in a geographic information system (GIS) atmosphere for waste site issues in the South of Texas. Ghianiet al. [18] proposed an appropriate integer programming model for the site of collection points with limited capacity in a waste collection management scheme. Also, Ghiani et al. [19] revealed that the efficiency of locating the collection points by zoning the service sites. Eiselt and Marianov [20] applied dissimilar location models for gathering facilities of MSW. Sabir et al. [1] examined the solid waste management (SWM) process and implementation in the megacity Karachi and also investigated challenges faced by the liable establishment. Rathore and Sarmah [21] used a MILP-model for the lack of waste transfer station and their proper location for the segregation of waste material. Some scientists have worked on preventing solid waste material and suggested recycling waste to make new products and waste management $[22,23]$.

The appraisal of MSW is very significant for policymakers and scientists, because it deteriorate human health and the environment [4]. Furthermore, to understand that political instability, disappointing policies, and negligence of this department at the government level are responsible for the haphazard situation for this department. Now the administration of the city has made an agreement with a Chinese company for the betterment of the remaining pileup of waste in the city. This company has used its machinery (loader and dumper), but the circumstances are not so good. Globally waste production has been increased this is a time of the revival of nature to reuse things that possible. An increase in population growth is the main factor of waste generation in rural areas, solid waste management has not a big issue because they have been reused all things and usage of packaging goods are so minimized in these areas. In Karachi, 
various initiatives have been taken to control the havoc condition of solid waste in which contract with the Chinese company has been also very important. Up to date, very limited information is available on the municipal solid waste collection, transfer, recycling, and proper disposal in this area. However, to fill this research gap the present study evaluates the current scenario of municipal solid waste through GIS techniques. In light of the existing work, this research work aimed to assess the population density, municipal solid waste generation rate, collection, transportation, and disposal of MSW through GIS techniques in the megacity Karachi.

\section{Materials and Methods Study design}

In this study, quantitative and qualitative types of data have been used for the assessment of solid waste management systems. The data was gathered from different sources including web pages, newspapers, published material, books as well as government organizations. MSW (CDGK) was used for recognizing ground reality photography which may play a very important role in this investigation. The MSW collection and vehicles are imperative essentials to handle the circumstance of MSW management. In addition, to investigate the real facts, interviews of the vehicle drivers have also been conducted to recognize the type and waste carrying capacities of vehicles because it was a quite difficult task. Population and waste generation are closely associated with each other for their analysis spearman's rank correlation coefficient method has been used. The population-density was calculated in this present work by using ArcGIS 10.3.1. In order to calculate the population density some very important steps has been used, firstly area was calculated by geometry calculation tool than calculate population density by using following formula. Population Density $=$ Population/Area $(\mathrm{sqkm})$

\section{Setting}

Karachi is a megacity and contributing significant role in Pakistan economy. It is situated in the province of Sindh having latitude and longitude of Karachi are: $24^{\circ} 54^{\prime} 20.16^{\prime \prime} \mathrm{N}$, $67^{\circ} 4$ ' $55.92^{\prime}$ 'E

Furthermore, it has been divided into five district viz., Karachi East, Karachi West, Karachi Central, Karachi South and Malir districts, while in November 2013 a new District (6th), Korangi was created by splitting district Karachi East the districts of Karachi further divided into 18 towns namely Orangi, Lyari, Saddar, Site, Kemari, Jamshed, Baldia, Landhi, Shah-Faisal, New Karachi, Korangi, Gulberg, Gulshan, Malir, Bin Qasim, Liaquatabad, Gadap and N. Nazimabad (Fig. 1).

\section{Variables}

\section{Dependent variable}

The dependent variable in this study is the waste generated per day (ton). Waste generation per day (ton), data of 2019 of different towns of Karachi has been used for analysis.

\section{Independent variables}

In this study for assessment, the Spearman correlation method has been used population is an independent variable so we plot it on the $\mathrm{x}$-axis. While, increasing population with limited sources is an alarming indicator for a city.

\section{Data sources/measurement}

In this study, secondary data were collected from the official source of national census 2017 and semi-official sources of district councils.

\section{Population density calculation through ArcGIS}

The multicultural city affords the problem of a remaining pileup of waste with significantly rising of human population. In contrast, the city has not been facilitated with the raise of population which formed disorganized conditions for citizens. To address this circumstance for analysis of 
population density was calculated in this study by using ArcGIS 10.3.1, a method for population density calculation as given in (Fig. 2).

\section{STUDY AREA:KARACHI}

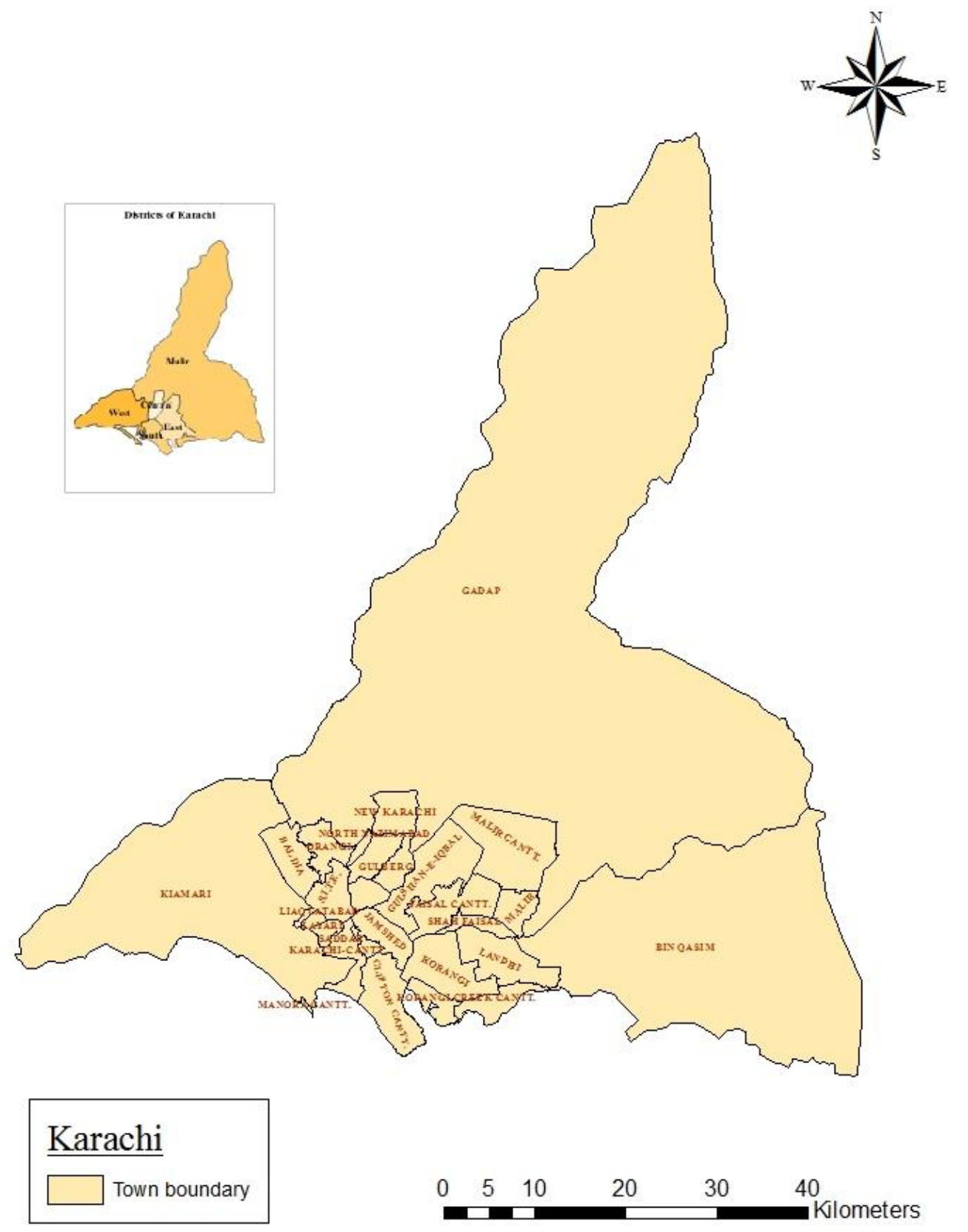

Figure 1. Study Area of Karachi, Source: Author 


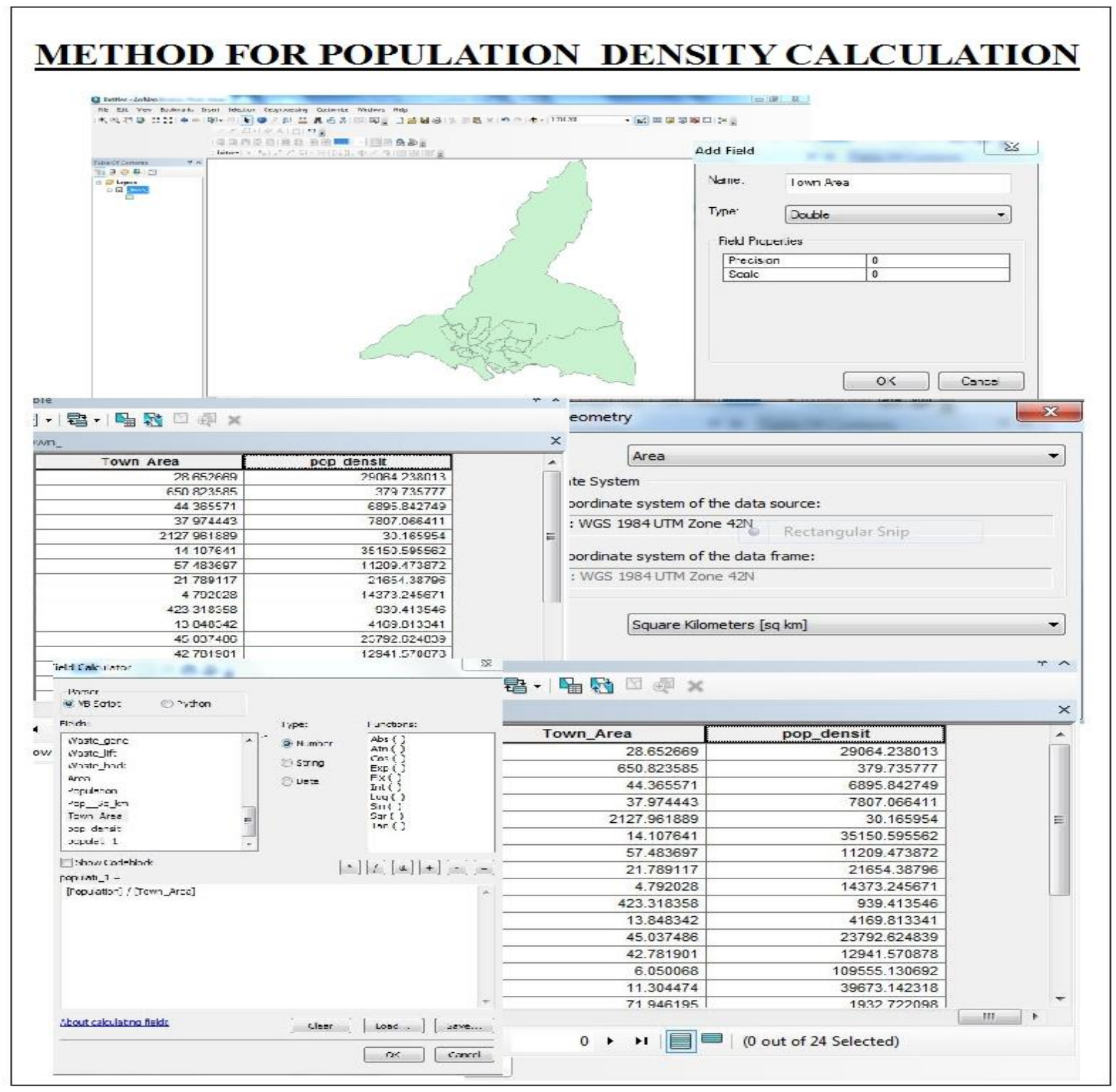

Figure 2. Method for population density calculation, Source: Author

The (Fig. 3) shows the population density of Karachi towns. Lyari, Liaquatabad, Gulberg, North Nazimabad, New Karachi, Shah Faisal towns are representing huge population, whilst (Table 1), revealed apparent facts regaring population, area, and population density in dissimilar towns of Karachi.

The Per capita MSW generation in the megacity was $0.5 \mathrm{~kg}$ per person per day and approximately 2929402.293 tons per year. It is anticipated that an increase the MSW generation has significant correlation with dense population. As shown in (Fig. 4) indicated that the clear facts about the waste generated rate of Karachi, the town of Korangi, Saddar, New Karachi, and Baldia which represent the highest value in the given map. 


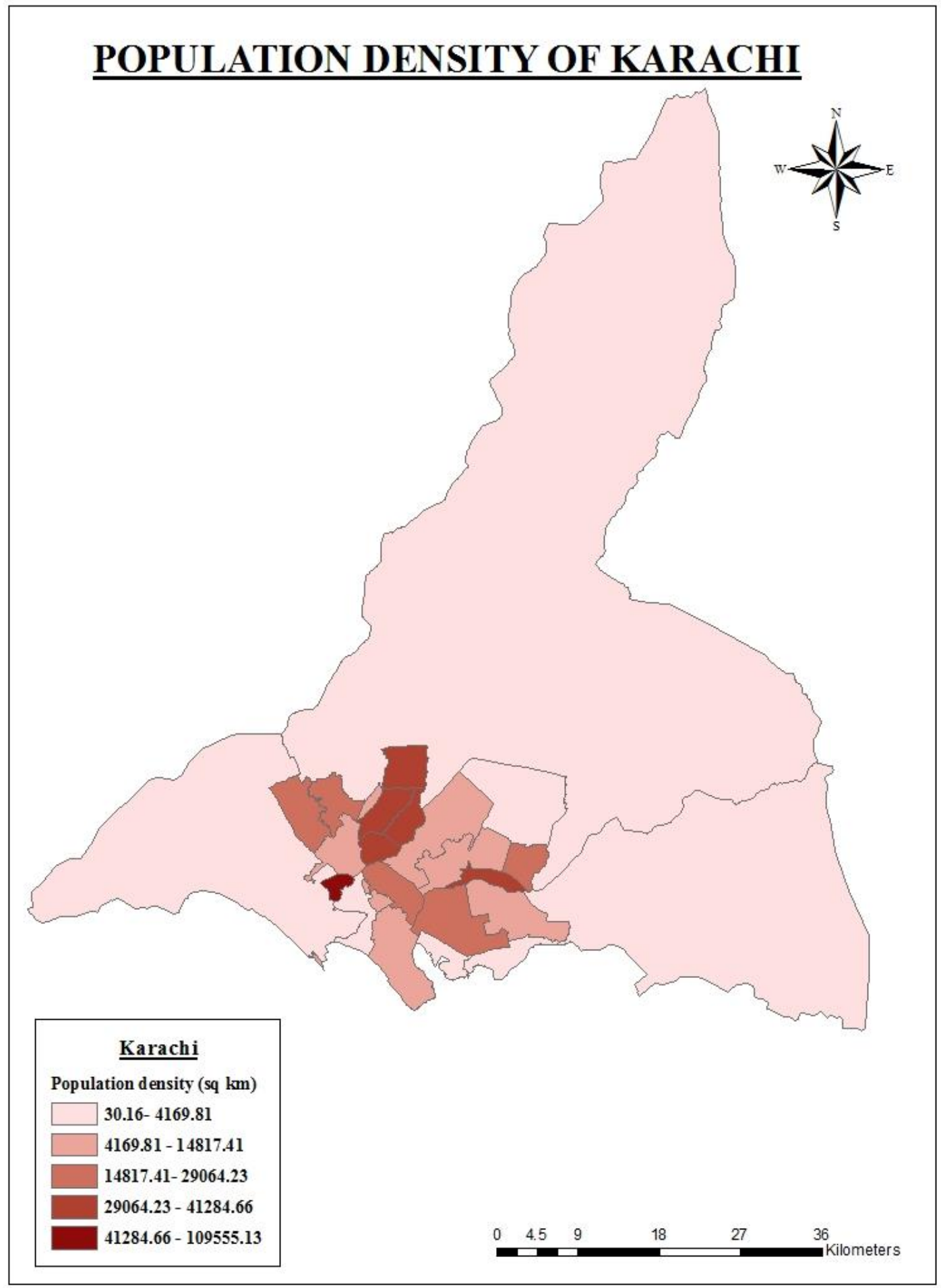

Figure 3. Population density of Karachi towns, 2017, Source: Author 
Table 1. Area, population, and population density in different towns of Karachi

\begin{tabular}{|c|c|c|c|c|c|c|}
\hline Fid & Shape & Town names & Count & Area (Km) & Population & $\begin{array}{c}\text { Population } \\
\text { density (Sq Km) }\end{array}$ \\
\hline 0 & Polygon & Baldia & 8 & 28.652669 & 832768 & 29064.23801 \\
\hline 1 & Polygon & Bin Qasim & 7 & 650.823585 & 247141 & 379.735777 \\
\hline 2 & Polygon & Clifton Cantt. & 1 & 44.365571 & 305938 & 6895.842749 \\
\hline 3 & Polygon & Faisal Cantt. & 1 & 37.974443 & 296469 & 7807.066411 \\
\hline 4 & Polygon & Gadap & 8 & 2127.961889 & 64192 & 30.165954 \\
\hline 5 & Polygon & Gulberg & 8 & 14.107641 & 495892 & 35150.59556 \\
\hline 6 & Polygon & Gulshan-E-Iqbal & 13 & 57.483697 & 644362 & 11209.47387 \\
\hline 7 & Polygon & Jamshed & 13 & 21.789117 & 471830 & 21654.38796 \\
\hline 8 & Polygon & Karachi-Cantt. & 1 & 4.792028 & 68877 & 14373.24567 \\
\hline 9 & Polygon & Kiamari & 8 & 423.318358 & 397671 & 939.413546 \\
\hline 10 & Polygon & KorangiCreek & 1 & 13.848342 & 57745 & 4169.813341 \\
\hline 11 & Polygon & Korangi & 9 & 45.037486 & 1071560 & 23792.62484 \\
\hline 12 & Polygon & Landhi & 12 & 42.781901 & 553665 & 12941.57088 \\
\hline 13 & Polygon & Layari & 11 & 6.050068 & 662816 & 109555.1307 \\
\hline 14 & Polygon & Liaquatabad & 11 & 11.304474 & 448484 & 39673.14232 \\
\hline 15 & Polygon & Malir Cantt. & 1 & 71.946195 & 139052 & 1932.722098 \\
\hline 16 & Polygon & Malir & 7 & 16.84774 & 454956 & 27003.97731 \\
\hline 17 & Polygon & Manora Cantt. & 1 & 0.755214 & 5874 & 7777.923986 \\
\hline 18 & Polygon & New Karachi & 13 & 21.103041 & 871232 & 41284.66669 \\
\hline 19 & Polygon & North Nazimabad & 10 & 17.26352 & 708583 & 41045.10629 \\
\hline 20 & Polygon & Orangi & 13 & 19.953676 & 520609 & 26090.88182 \\
\hline 21 & Polygon & S.I.T.E. & 9 & 27.316297 & 404757 & 14817.41848 \\
\hline 22 & Polygon & Saddar & 11 & 20.005357 & 36366 & 1817.81313 \\
\hline 23 & Polygon & Shah Faisal & 7 & 10.985282 & 447993 & 40781.20002 \\
\hline Source: Author Waste generation scenario of studied area & & \\
\hline
\end{tabular}

\section{Data analysis methods}

For the analysis of data Spearman's rank correlation coefficient (rs) method was used in this study. This was the most reliable technique to find out the correlation between the two variables. $T$ value and degree of freedom have also been calculated.

$\mathbf{r s}=1-6 \Sigma \mathbf{d}^{2} / \mathbf{n}^{3}-\mathrm{n}$

Where: $d=$ the difference in rank of the values of each matched pair.

$n=$ the number of pairs

$\Sigma=$ the sum of

\section{Results}

Spearman's rank correlation coefficient

In this present work, the association between population and waste producing was carried out by using Spearman's rank correlation technique, that can be used understand the correlation among two variables. The data in (Table 2) showed that two data sets of the population and waste producing per day (ton) form unlike towns of Karachi, the ranking has been specified to two data sets separately from maximum to minimum level. 


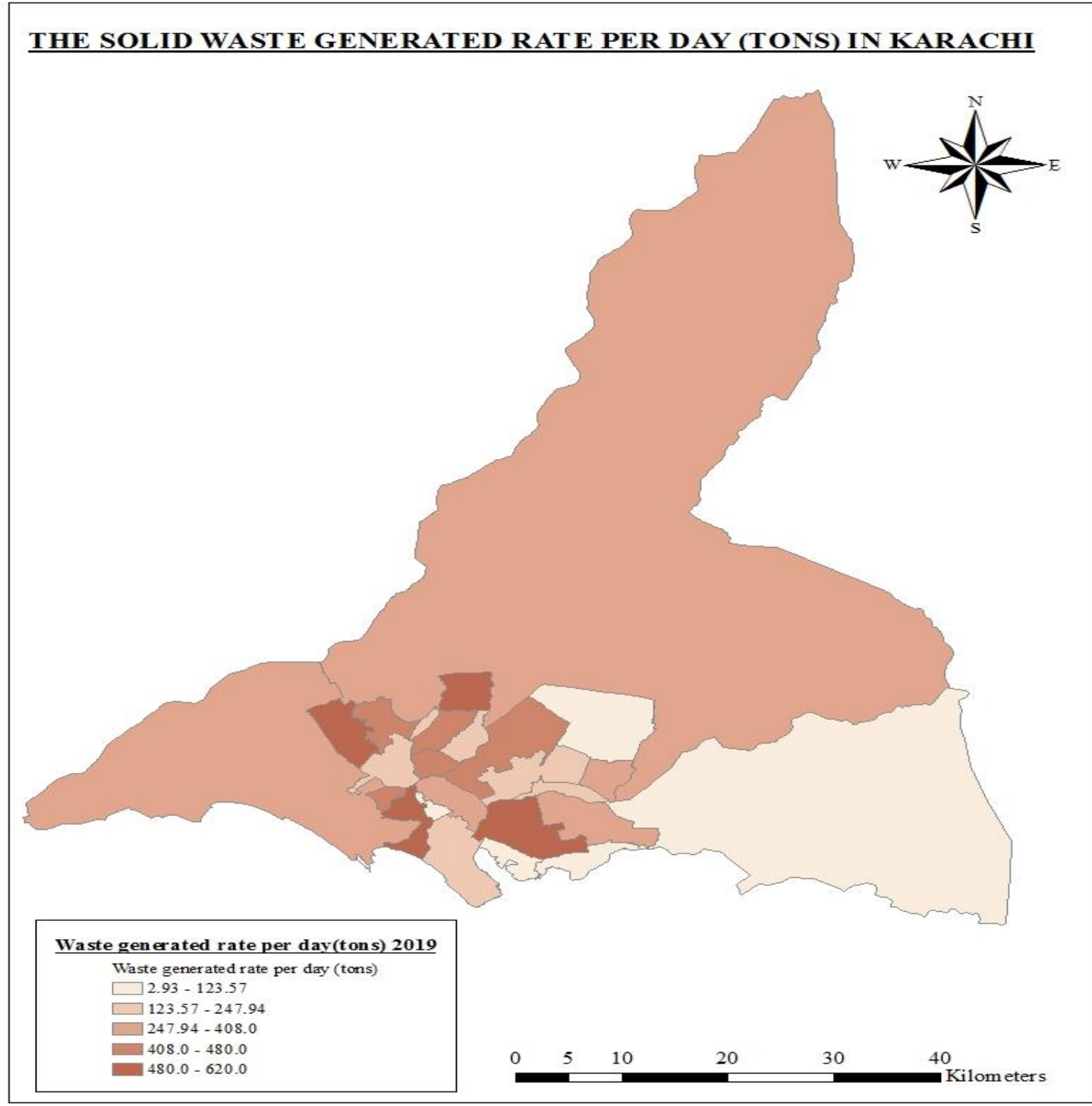

Figure 4. Solid waste generated per day (Ton) of Karachi at the town level in 2019. Data Source: SWM, CDGK

$$
\begin{aligned}
r s & =1-\frac{6 \Sigma \mathrm{d}^{2}}{\mathrm{n}^{3}-\mathrm{n}} \\
r s=1 & -\frac{6 \Sigma 713}{(24)^{3}-24} \\
& =0.69
\end{aligned}
$$

Rejection level $(\alpha)=95 \%$

$$
\begin{aligned}
& =0.05 \\
\mathrm{t} & =r s \sqrt{\frac{n-2}{1-r s^{2}}} \\
& =0.69 \sqrt{\frac{24-2}{1-(0.69)^{2}}}
\end{aligned}
$$




$$
\begin{aligned}
& \mathrm{df}=(\mathrm{n}-2)^{\mathrm{t}=4.47} \\
& \mathrm{df}=22
\end{aligned}
$$

Rejection level $=0.05$

Critical value of $\mathrm{t}=2.07$

The obtained data revealed that the significant value of $t$ test is less than our $t$ level (4.47), which represent the association among population and waste generation, while the level of rs was 0.69 . It shows that there is a significant positive correlation was observed in among two variables. As data in

\begin{tabular}{|c|c|c|c|c|c|c|}
\hline Towns & Rank & Waste generation (ton) per day & Population & Rank & $\mathbf{D}$ & $d^{2}$ \\
\hline Layari & 8 & 420 & 662816 & 5 & -3 & 9 \\
\hline New Karachi & 3 & 530 & 871232 & 2 & -1 & 1 \\
\hline North Nazimabad & 5 & 480 & 708583 & 4 & -1 & 1 \\
\hline Shah Faisal & 16 & 223.9965 & 447993 & 13 & -3 & 9 \\
\hline Liaquatabad & 6 & 450 & 448484 & 12 & 6 & 36 \\
\hline Gulberg & 15 & 247.946 & 495892 & 9 & -6 & 36 \\
\hline Baldia & 4 & 500 & 832768 & 3 & -1 & 1 \\
\hline Malir & 12 & 320 & 454956 & 11 & -1 & 1 \\
\hline Orangi & 9 & 410 & 520609 & 8 & -1 & 1 \\
\hline Korangi & 1 & 620 & 1071560 & 1 & 0 & 0 \\
\hline Jamshed & 10 & 408 & 471830 & 10 & 0 & 0 \\
\hline S.I.T.E. & 17 & 202.378 & 404757 & 14 & -3 & 9 \\
\hline Karachi-Cantt. & 23 & 34.4385 & 68877 & 20 & -3 & 9 \\
\hline Landhi & 13 & 305 & 553665 & 7 & -6 & 36 \\
\hline Gulshan-E-Iqbal & 7 & 430 & 644362 & 6 & -1 & 1 \\
\hline Faisal Cantt & 19 & 148.2345 & 296469 & 17 & -2 & 4 \\
\hline Manora Cantt & 24 & 2.937 & 5874 & 24 & 0 & 0 \\
\hline Clifton Cantt & 18 & 152.969 & 305938 & 16 & -2 & 4 \\
\hline $\begin{array}{c}\text { Korangi Creek } \\
\text { Cantt }\end{array}$ & 22 & 48 & 57745 & 22 & 0 & 0 \\
\hline Malir Cantt & 21 & 69.526 & 139052 & 19 & -2 & 4 \\
\hline Saddar & 2 & 600 & 36366 & 23 & 21 & 441 \\
\hline Kiamari & 14 & 290 & 397671 & 15 & 1 & 1 \\
\hline Bin Qasim & 20 & 123.57 & 247141 & 18 & -3 & 9 \\
\hline Gadap & 11 & 390 & 64192 & 21 & 10 & 100 \\
\hline & & & & & & $\begin{array}{l}\Sigma= \\
713 \\
\end{array}$ \\
\hline
\end{tabular}
(Fig. 5) revealed that the optimistic correlation between two variables.

Table. 2 Ranking of data sets 


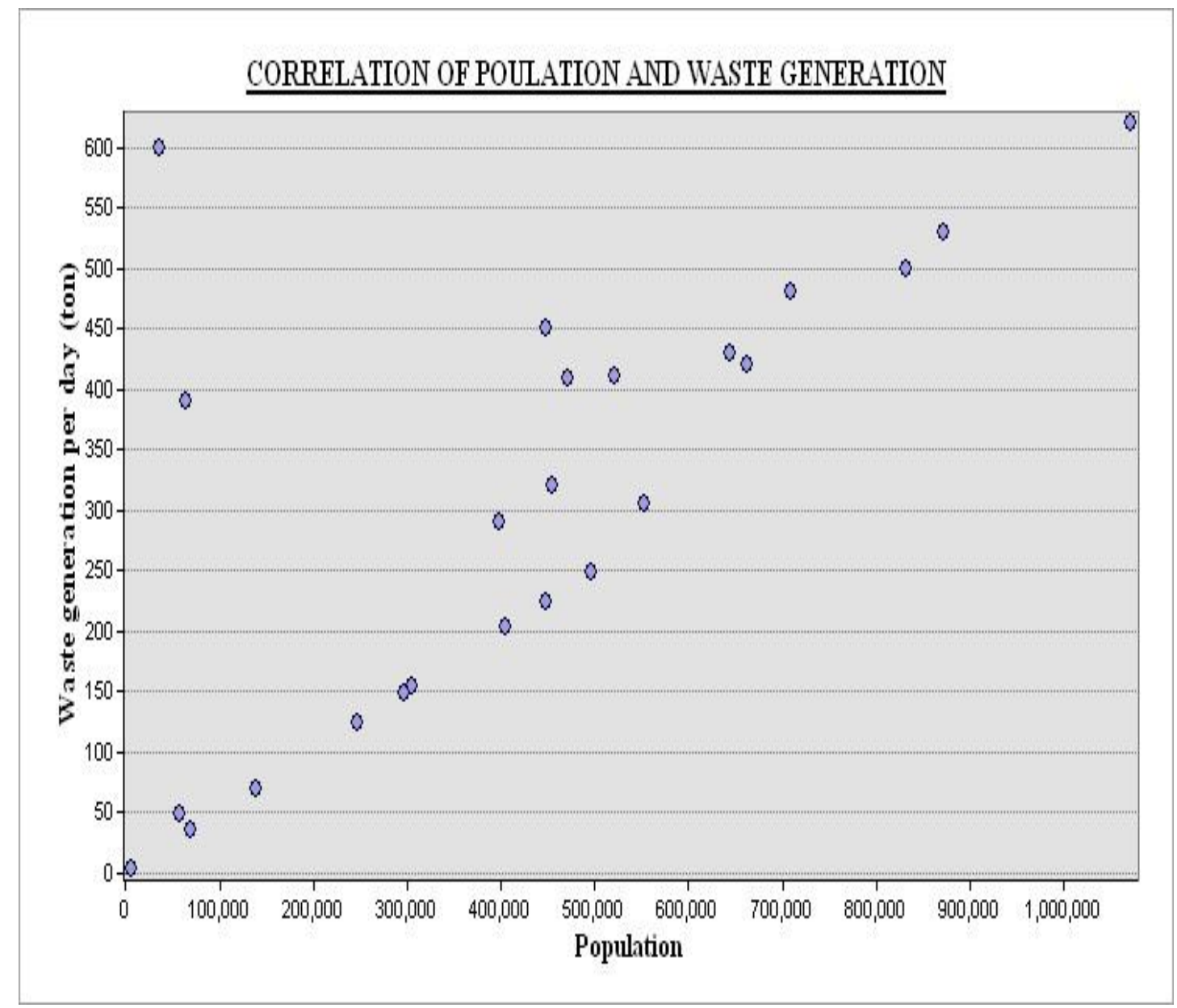

Figure 5. Correlation between population and waste management. Source, Author

Problems linked with solid waste management system in Karachi

The per capita MSW generation had been a significant challenge for a megacity Karachi, Pakistan. It is assumed that the rising MSW generation rate with directly correlated with the dense population because of the merge population. Unfortunately, other key factors are also responsible including, political instability is responsible for a disappointing performance in the field of solid waste management at the government level turned backlog issue disastrous in the time of monsoon because sewage nalas (streams) has been full of waste and drainage system of is collapsed in the time of the rainy season which exposed unsatisfactory performance of the municipal administration. Waste has been collected from houses in mixed form, because of lack of facilities it was very difficult for sanitary workers to separate recycling material at the primary stage. The non-government sector was engaged to manage MSW from city, they are paying Afghan waste pickers to collect the MSW from the community bins to open dumping site. In addition, Afghan waste collectors found to be very beneficial for clean-up waste material, but they also proliferate waste around the bins and congested roads. The data in (Fig. 6a) shows the pile-up of waste in the front of the flats. As exposed in (Fig. 6b) highlighted that the waste pickers are collecting the reusable item from a heap of waste. The data in (Fig. 6c) shows burning 
waste along the road. (Fig. 6d) represents a heap of waste in an open plot.

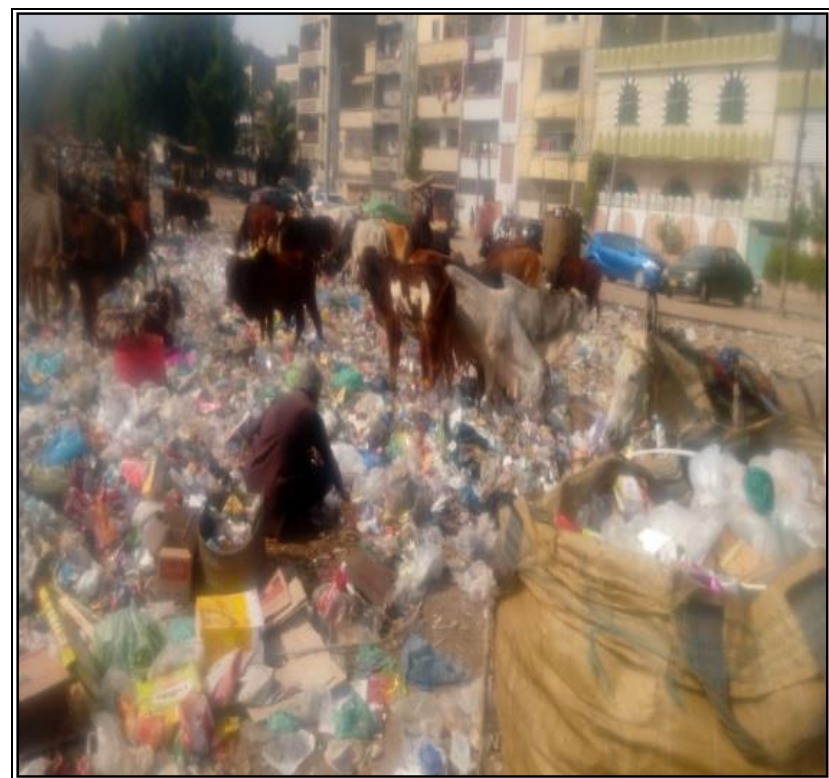

(a) Pile-up of waste.

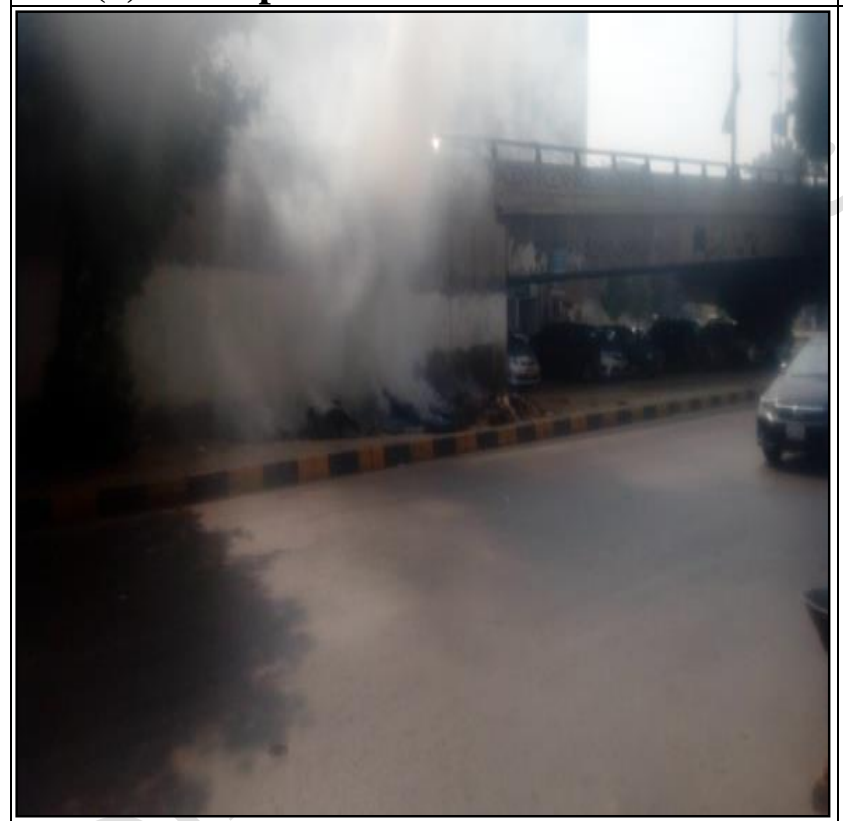

(c) Burning waste along the road

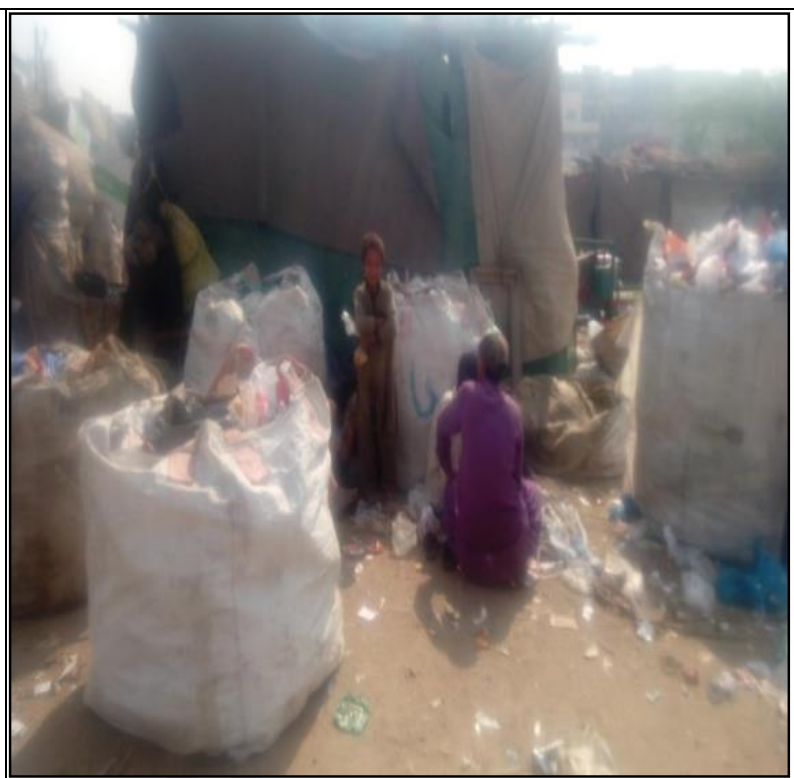

(b) Collecting reusable item

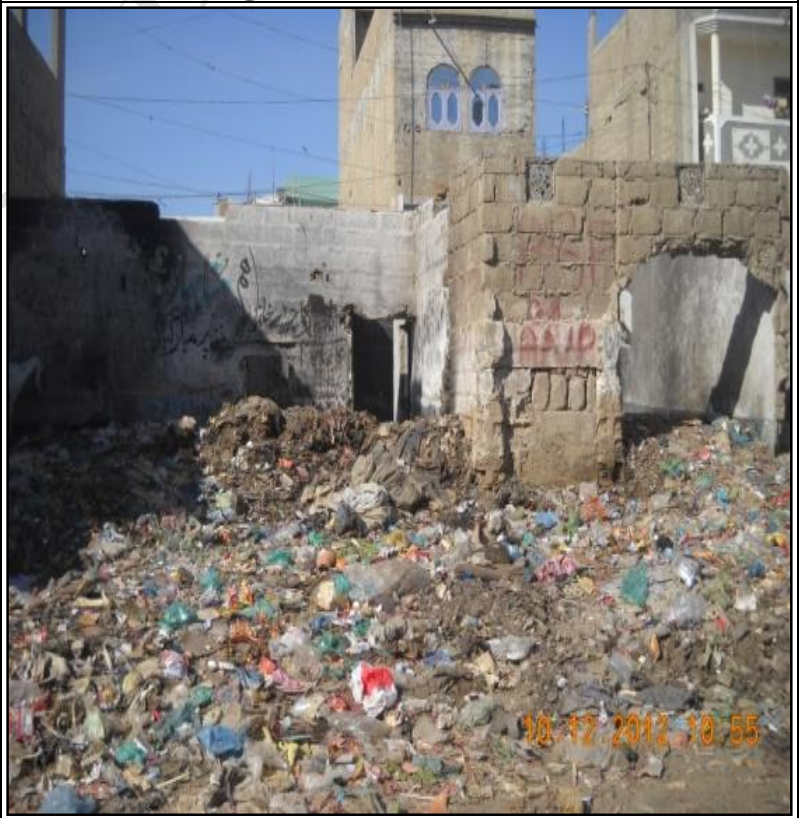

(d) A heap of waste in an open plot

Figure 6. Shows ground truthing, (a) Pile-up of waste, (b) Collecting reusable item, (c) Burning waste along the road, (d) A heap of waste in an open plot, Source: Author

Means of transportation in solid waste management

The collection of MSW from waste collection points by using different vehicles has found to be very importance to handle the situation of MSW in any area; however present study found that insufficient number of vehicles in the mega city Karachi (Fig. 7), which represents the different kinds of the vehicle of the government, the majority of 
which are not functional. Only North Nazimabad, Cantonment, Central district, and some areas of east districts served by government vehicles, and all Karachi is served by private contractor vehicles and Chinese companies. The data in (Fig. 8) indicated the types of vehicle have used in waste collection and transportation. Each vehicle is making 3 to 4 trips per day from the collection points to the dumping areas Chingchi Rickshaw, motorcycle trolley, Mini tractor-trolley collects waste from the small, thin, and congested route and filled waste through labor old compacted dumper also gather waste from small routes filled through labor. Medium dumper, big dumper, mini dumper, medium tractor trolley was filled with the assist of a loader and follow the main route for transportation of waste to final dumping sites. The types of vehicles and their capacity are indicated in (Table 3 ).

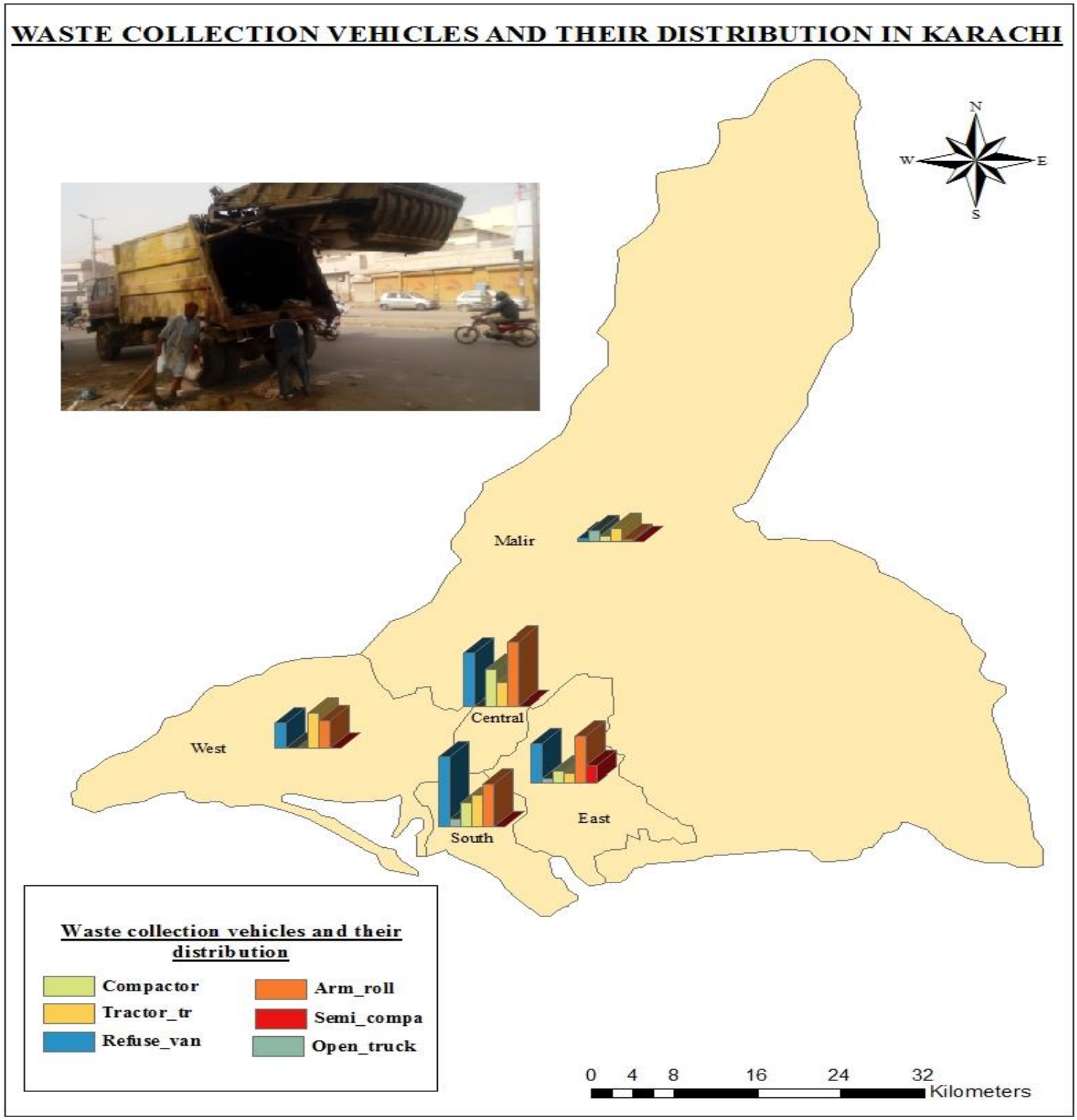

Figure 7. Government waste collection vehicles and their distribution in Karachi, Data Source: Ali and Hasan [24]. 


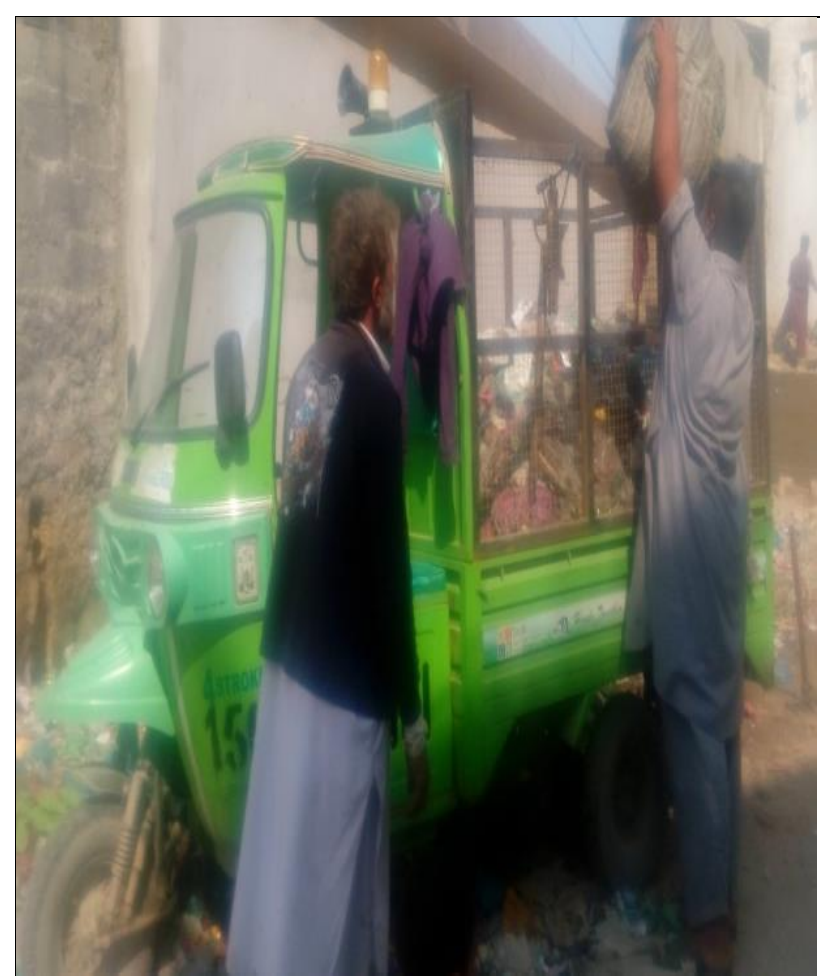

a) Ching-chi Rikshaw

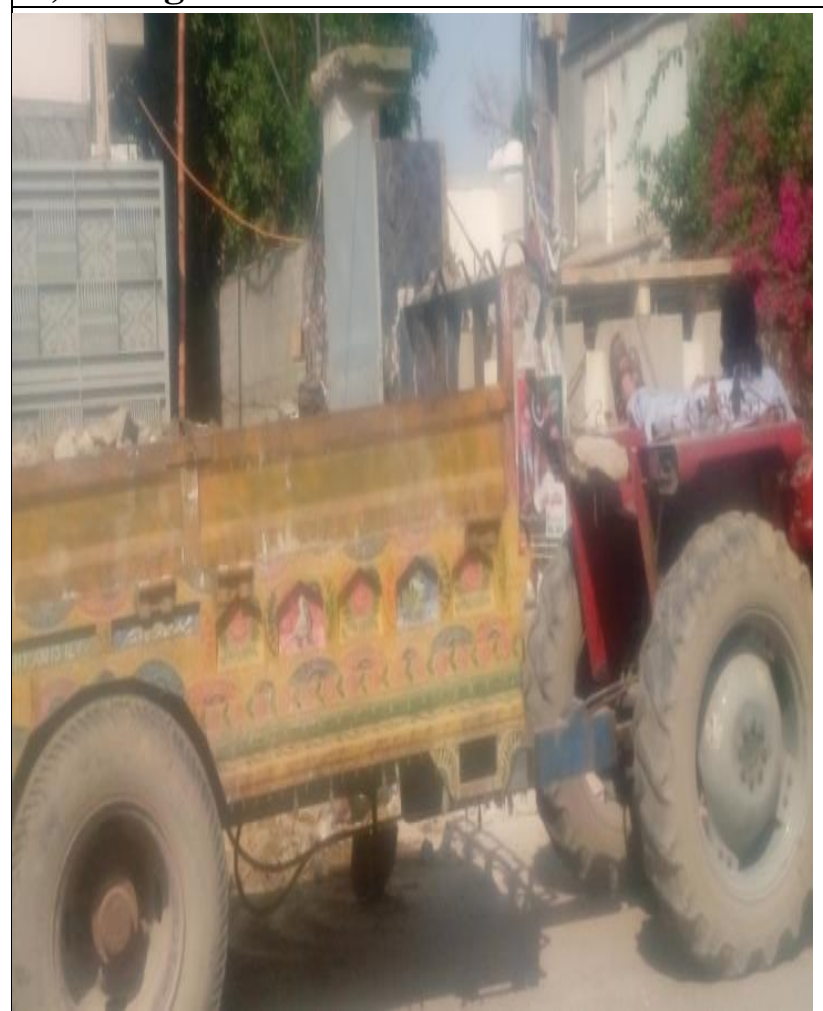

c) Mini Tractor Trolley

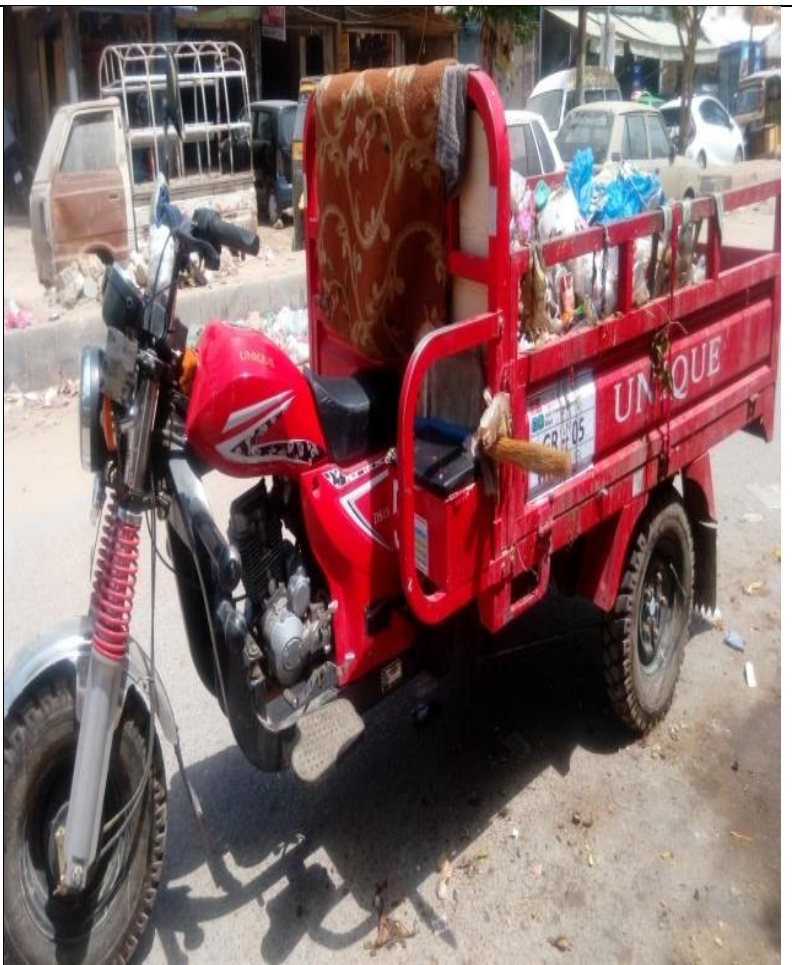

b) Motorcycle Trolley

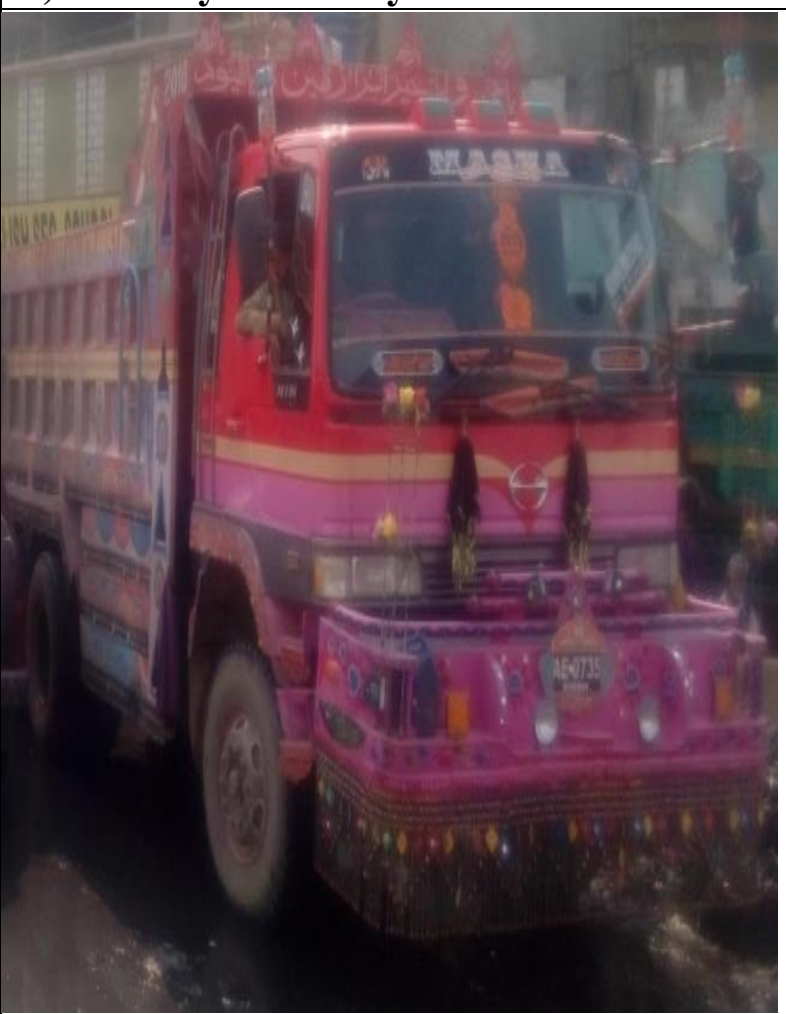

d) Medium Dumper 
Afzal et al.

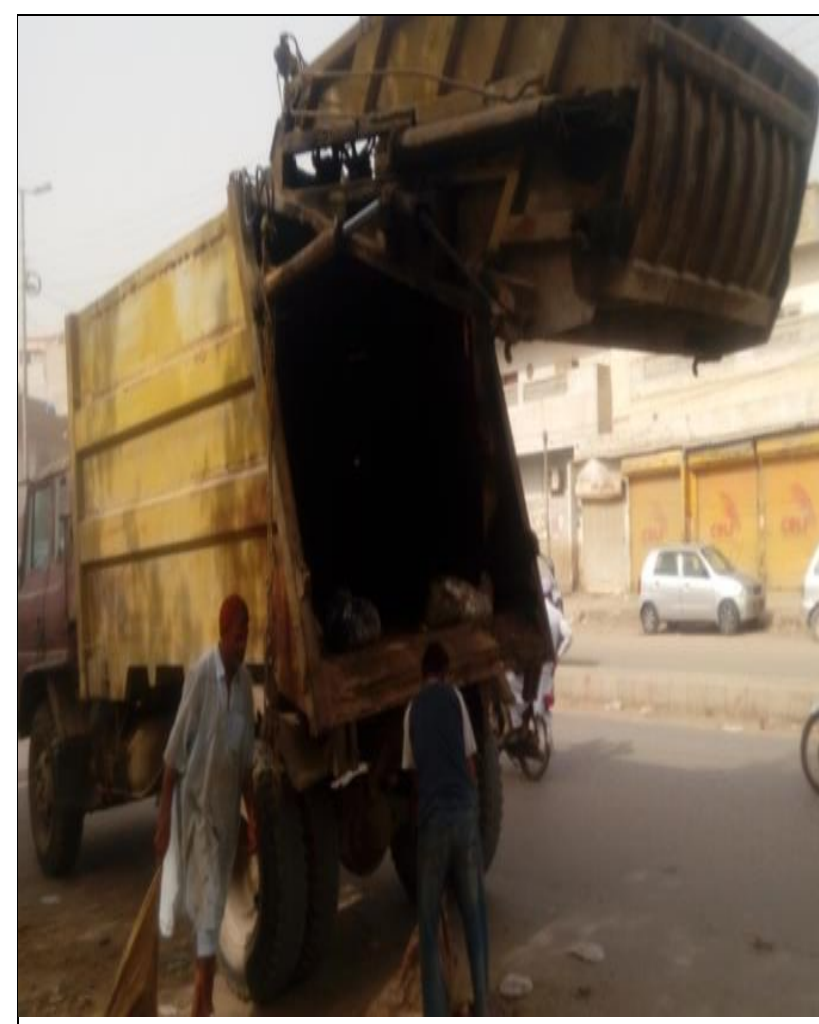

e) Old Compress Dumper
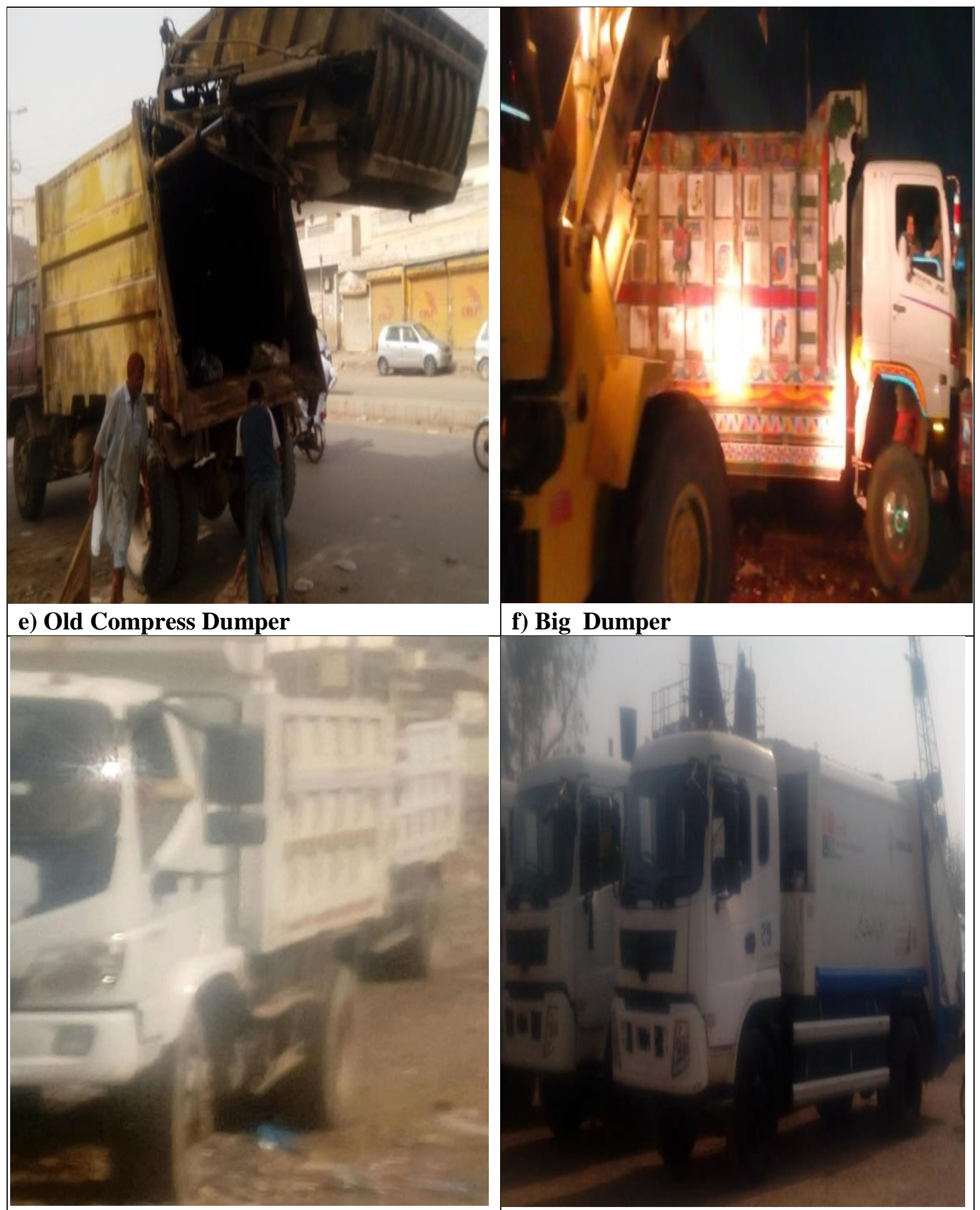

f) Big Dumper

g) Mini Dumper

h) Big Compactor Dumper 


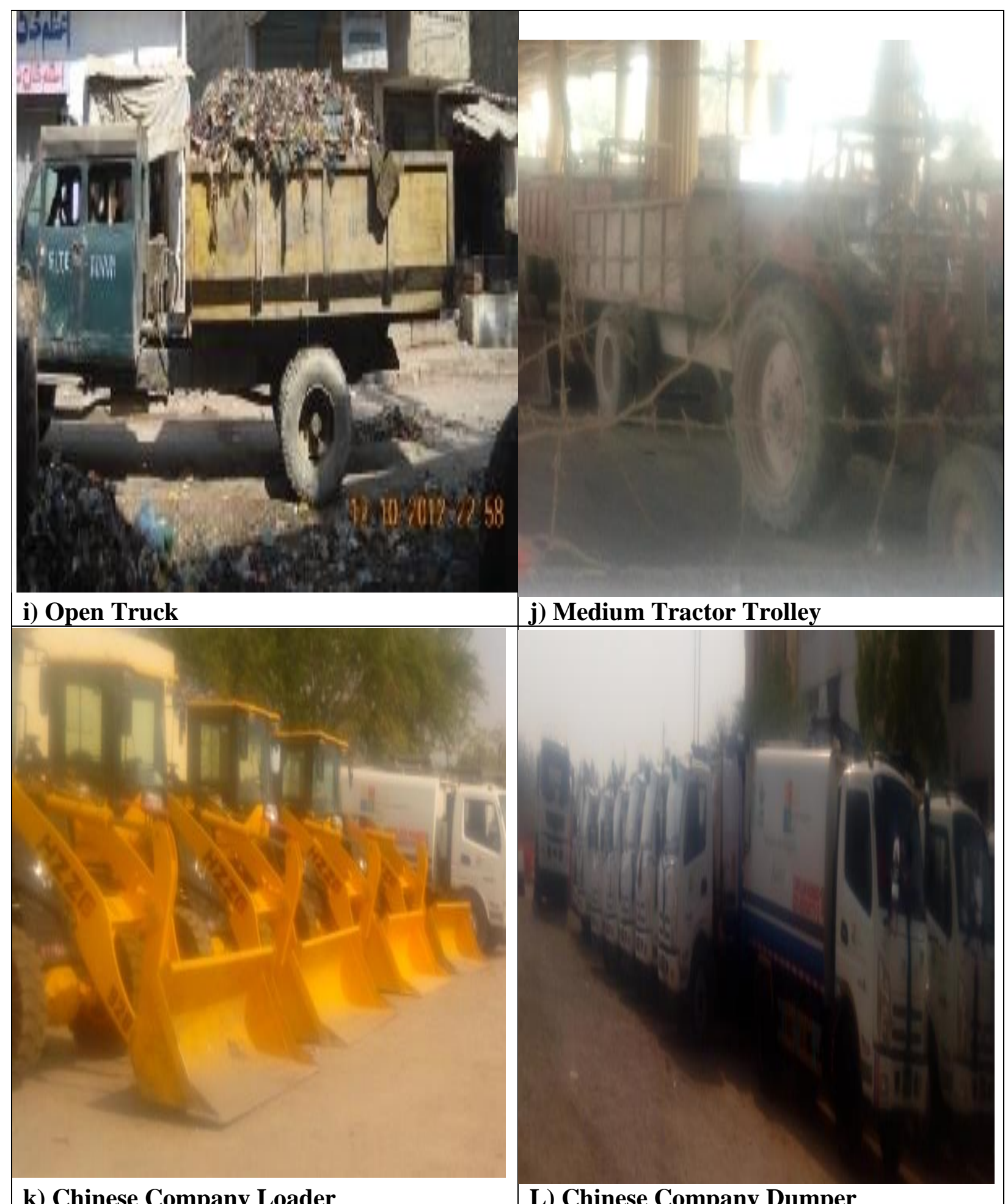

k) Chinese Company Loader

L) Chinese Company Dumper

Figure 8. Types of vehicles used in waste collection and transportation (a) Ching-chi Rikshaw, (b) Motorcycle trolley, (c) Mini tractor trolley, (d) Medium dumper, (e) Old compress dumper, (f) Big dumper, (g) Mini dumper, (h) Big compactor Dumper, (i) Open truck, (j) Medium tractor trolley, (k) Chinese company loader, and (l) Chinese company dumper, Source: Author 
Table 3. Different types of vehicles and their load capacity

\begin{tabular}{|c|c|c|}
\hline S. No. & Type & Capacity \\
\hline 1 & Ching-chi Rikshaw & 600 to $700 \mathrm{~kg}$ \\
\hline 2 & Motorcycle trolley & 600 to $700 \mathrm{~kg}$ \\
\hline 3 & Mini Tractor trolley & 1.5 to 2 tons \\
\hline 4 & Medium Dumper & 12 to 14 tons \\
\hline 5 & Mini Compress Dumper & 3 to 4 tons \\
\hline 6 & Big Dumper & 18 to 2 o tons \\
\hline 7 & Mini Dumper & 7 to 8 tons \\
\hline 8 & Big Compactors Dumper & 6 to 8 tons \\
\hline 9 & Loader & Loading \\
\hline 10 & Tractor trolley & 3 to 4 tons \\
\hline 11 & Tractor trolley & 1.5 to 3 tons \\
\hline 12 & Vehicles of the Chinese company & 4 to 10 toms \\
\hline 13 & Arm Roll & 5 to 6 tons \\
\hline
\end{tabular}

Source: Author

Influence of seasons on volume and quantity of the municipal solid waste

The improper treatment and disposal methods of MSW management in the study area, which contributing Backlog quantity has been growing in Karachi, because of inappropriate situation and lack of bins from fundamental waste collection units. General, the people throw their garbage to streets, unconstructed plots, footpaths and nalas (streams) dumping of waste in drainage system resulting blocking the drainage system and causing several human health serious for example, electric specially heavily rainfall in monsoon season. As shown in (Fig. 9) highlighted the influence of seasons on volume and quantity of MSW.

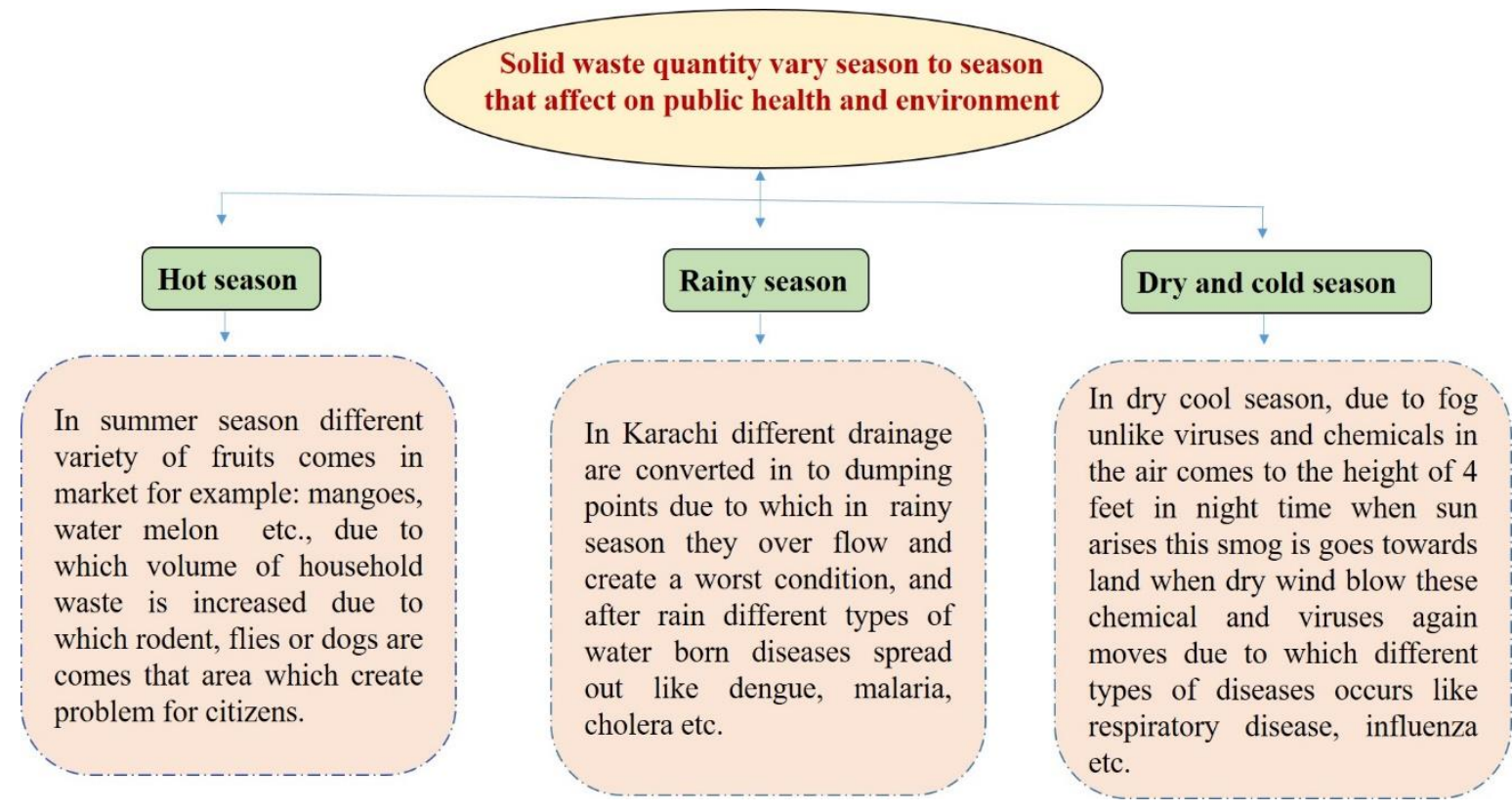

Figure 9. Impact of seasons on volume and quantity of solid waste, Source: Author 


\section{Discussion}

This study has highlighted the issues faces municipal solid waste system in a multicultural city, assessment has been done through GIS Techniques statistical analysis of two variables have done, a positive correlation has found between population and waste generated rate per day (tons), qualitative assessment of means of transportation of solid waste also included and identified the types of vehicles with the help of pictures and explains their capacity which is very beneficial for policymakers and researchers to reduce the waste pileup by making proper strategy. The impact of the seasons shows their importance regarding municipal solid waste management. Mostly developing cities are facing a big challenge of solid waste management. Abbasi et al. [5] stated that the climate of megacity Karachi can be characterized by humid and moderate to hot circumstances. The mean lower $0^{\circ} \mathrm{Cand}$ highest $47^{\circ} \mathrm{C}$ may vary in the summer season; furthermore, the average rainfall at Karachi is about $203 \mathrm{~mm}$. It is assumed that the variation in temperature and rainfall may directly impact municipal solid waste generated, onsite handling, and management. Research work was carried about the possibility of energy generation from municipal solid waste (MSW) in Pakistan Korai et al. [25], predictable that the hypothetical biogas potential for MSW generated in the megacity Karachi by using elemental analysis. Furthermore, Khan et al. [26] revealed that Karachi city has a population of about 20 million and generating 14,000 tons of MSW per day. Meanwhile, findings showed that no proper MSW management in this megacity and posing a risk to soil pollution, ground water marine life, and greenhouse gas emission in the air. Khan et al. [27] suggested that the application of decision support software for Karachi revealed that the current development needs to be reconsidered and land-filling of RDF/ SRF to be converted by waste-to-energy options. Hoque and Islam [28] stated that composting is a very important method and completed in 40-45 days in this time $50-55 \%$ of the volume of waste is reduced from its original volume. Ali et al. [29] used the broad indicators to rank MSW in a major city and suggested that the integrated waste disposal systems to mitigate the GMGs emission to atmosphere. Siddiqi et al. [30] indicated that recyclable paper and plastics removed from MSW can produce nearly 290 gigawatt hours (GWh) in Karachi and $60 \mathrm{GWh}$ in Delhi. Safar et al. [31] reported some recycling components for converting MSW into energy recovery and minimizing environmental pollution.

\section{Conclusion and Recommendations}

We concluded that there have lots of issues presents in existing solid waste management system, due to which it never shows better progress, waste collection, and vehicles are very significant components for management of MSW form waste collection generated points, but unluckily vehicles are inadequate to lift total MSW material from bins to disposal sites of Karachi. The population was another important indicator for the generation of waste in a city for analysis population density which was calculated in this study by using ArcGIS 10.3.1. The variation of seasons, i.e. rainy, hot, cold also affects the quantity and volume of solid waste community bins are a fundamental element of the solid waste management system so their proper placement and maintenance are very important. The followings are the significant contributions of the present study: - The municipal solid waste generation is approximately 2929402.293 tons per year, and its volume and quantity varies from season to season, waste generation rate per day tons 2019 map of Karachi is very helpful for risk evaluation of the city.

- Spatial distribution of waste collection vehicles in Karachi through ArcGIS 
techniques evaluated the basis for future waste collection vehicles planning and waste management projects.

- The study has calculated the correlation between population and waste generated rate per day (tons) indicated beneficial for future planning in the city, guide them as to where the future waste management service's related activities should establish.

- Burning and open dumping are common methods are practicing for waste treatment, it extremely recommended that compost technology should be practiced in this region to manage organic waste material, because it a robust low cost and an eco-friendly technology. The government should take interest to manage solid waste management and provide awareness programs and as well as training to waste collection workers. Finally, it is suggested that the eco-friendly integrated waste management practices should be introduced to manage MSW material, for example biodegradable waste material should be converted into make compost, bio fertilizers, biochar etc., and non-biodegradable waste material can be converted to make smart biochar, road construction material, energy recovery and gold recovery specially from e-waste.

\section{Authors' contributions}

Conceived and designed the experiments: A Afzal \& SAfsar, Performed the experiments: A Afzal, Analyzed the data: A Afzal, Contributed materials/ analysis/ tools: A Afzal \& SAfsar, Wrote the paper: A Afzal \& AH Lahori.

\section{Acknowledgment}

I express my sincere gratitude to $\mathrm{Mr}$. ImranAslam (Administrator DMC.West), Mr. Muhammad Anwar (Ex.DTO, Site), Mr.MuhammadRafeeq (DTO Site), Mr. Muneer Ahmed (ATO) sanitation department, for providing vital statistics on waste.

\section{References}

1. Sabir W, Waheed SN, Afzal A, Umer SM \& Rehman S (2016). A study of solid waste management in Karachi city. $J$ Educ Soc Sci 4 (2): 151-163.

2. Sohoo I, Ritzkowski M, Heerenklage J \& Kuchta K (2021). Biochemical methane potential assessment of municipal solid waste generated in Asian cities: A case study of Karachi, Pakistan. Renew Sust Energ Rev 135: 110175.

3. Shaikh A \& Hussain MA (2019). A novel mathematical model for solid waste district malir, Karachi. 2019 2nd Int Conf Comput Math Eng Technol 1-8.

4. Tirkolaee EB, Mahdavi I, Esfahani MMS \& Weber GW (2020). A robust green location-allocation-inventory problem to design an urban waste management system under uncertainty. Waste Manag 102: 340-350.

5. Abbasi HN, Lu X \& Zhao G. (2015). An overview of Karachi solid waste disposal sites and environs. J Sci Res Rep 294303.

6. Korai MS, Mahar RB \& Uqaili MA (2016). Optimization of waste to energy routes through biochemical and thermochemical treatment options of municipal solid waste in Hyderabad, Pakistan. Energy Convers Manag 124: 333-43.

7. Sahu AK (2007) Present scenario of municipal solid waste (MSW) dumping grounds in India.Proceedings of the International Conference on Sustainable Solid Waste Management, Chennai, India. 327-333.

8. Kumar S, Bhattacharyya J, Vaidya A, Chakrabarti T, Devotta S \& Akolkar A (2008). Assessment of the status of municipal solid waste management in metro cities, state capitals, class I cities, and class II towns in India. Waste Manag (29): 883-895. 
9. Hamid A (2009). Urbanization, city growth and quality of life in Pakistan. Eur JSoc Sci (10): 196-215.

10. Guerrero LA, Maas G \& Hogland W (2013). Solid waste management challenges for cities in developing countries. Waste Manag 33(1): 220-232.

11. Valerio F (2009). Environmental impacts of postconsumer material managements: Recycling, biological treatments, incineration. Waste Manag 30(11): 2354-2361.

12. Rada EC, Istrate IA, Panaitescu V, Ragazzi M, Cirlioru TM \&Apostol T (2010). A comparison between different scenarios of Romanian municipal solid waste treatment before landfilling. Environ Eng Manag J 9(4): 589-596.

13. Ionescu G, ZardiD, Tirler W, Rada EC \&Ragazzi M (2012). A critical analysis of emissions and atmospheric dispersion of pollutants from plants for the treatment of residual municipal solid waste.UPB Scientific Bulletin Series D 74(4): 227-240.

14. Devi Y (2009). Studies on municipal solid waste management in Mysore CityA case study. Rep Opin 1(3):15-21.

15. Ionescu G, Rada EC, Ragazzi M, Marculescu C, Badea A \& Apostol T (2013). Integrated municipal solid waste scenario model using advanced pretreatment and waste to energy processes. Energ Convers Manag (76): 1083-1092.

16. Yesilnacar MI \& Cetin H (2005). Site selection for hazardous wastes: A case study from the GAP area, Turkey. Eng Geol 81(4): 371-388.

17. Chang NB, Parvathinathan G \& Breeden J.B (2008). Combining GIS with fuzzy multicriteria decision-making for landfill siting in a fast-growing urban region. $J$ Environ Manag 87(1): 139-153.

18. Ghiani G, Laganà D, Manni E \& Triki C (2012). Capacitated location of collection sites in an urban waste management system. Waste Manag 32(7): 1291-1296.

19. Ghiani G, Manni A, Manni E \& Toraldo M 2014. The impact of an efficient collection sites location on the zoning phase in municipal solid waste management. Waste Manag 34(11): 1949-1956.

20. Eiselt HA \& Marianov V (2015). Location modeling for municipal solid waste facilities. Comput Oper Res 62: 305-315.

21. Rathore P \& Sarmah SP (2019). Modeling transfer station locations considering source separation of solid waste in urban centers: A case study of Bilaspur city. India J Cleaner Prod 211: 44-60.

22. Cheikhrouhou N, Sarkar B, Ganguly B, Malik AI, Batista R \& Lee YH (2018). Optimization of sample size and order size in an inventory model with quality inspection and return of defective items. Ann Oper Res 271(2): 445-467.

23. Sarkar B (2019). Mathematical and analytical approach for the management of defective items in a multi-stage production system. J Cleaner Prod 218: 896-919.

24. Ali M \&Hasan A (2001). Integrating recycling and disposal system for solid waste management in Karachi. Urban Resource Centre.

25. Korai MS, Mahar RB \&Uqaili MA (2017). The feasibility of municipal solid waste for energy generation and its existing management practices in Pakistan. Renew Sustain Energy Rev 72: 338-53.

26. Khan S, Alvarez LCM \& Wei Y (2018). Sustainable management of municipal solid waste under changing climate: a case study of Karachi, Pakistan. Asian J Env Tech 2(1): 23-32. 
27. Khan WZ, Inglezakis $\mathrm{V}$, Ishtiaque $\mathrm{S}$ \&Moustakas K (2019). Assessment of municipal solid waste management practices in Karachi City, Pakistan. Int. J. Environ. Waste Manag 24(2): 131150.

28. Hoque MMM \& Islam S (2018). Temporal Changes of Physical Parameters of Solid Waste During Barrel Composting. J Environ Sci Nat Resour 11 (1\&2): 153-157.

29. Ali M, Geng Y, Robins D, Cooper D, Roberts W \& Vogtländer J (2019). Improvement of waste management practices in a fast expanding submegacity in Pakistan, on the basis of qualitative and quantitative indicators. Waste Manag 15(85): 253-63.

30. Siddiqi A, Haraguchi M \& Narayanamurti V (2020). Urban waste to energy recovery assessment simulations for developing countries. World Dev 131: 104949.

31. Safar KM, Bux MR, Faria U \& Pervez S (2021). Integrated model of municipal solid waste management for energy recovery in Pakistan. Energy 219: 119632. 